\title{
Diagnosis of invasive candidiasis in patients with and without signs of immune deficiency: a comparison of six detection methods in human serum
}

\author{
G-J PLATENKAMP,* A M VAN DUIN,* J C PORSIUS,* H J A SCHOUTEN, $\dagger$ \\ P E ZONDERVAN, $\ddagger$ M F MICHEL* \\ From the *Departments of Clinical Microbiology, $†$ Biostatistics, and $\ddagger$ Pathology, Erasmus University, \\ Rotterdam, The Netherlands
}

SUMMARY Visceral candidiasis in 56 patients, 39 of whom were thought to be immune deficient, was investigated using three serological detection methods-whole cell agglutination, haemagglutination, and counterimmunoelectrophoresis for antibodies; two determinations of circulating antigens-haemagglutination inhibition and latex agglutination; and determination of the arabinitol:creatinine ratio. Of the 39 patients with suspected immune deficiency, 13 had confirmed invasive candidiasis and 26 were colonised; of those without signs of immune deficiency, 10 patients also had invasive candidiasis and seven were colonised. Twenty three patients with invasive candidiasis were analysed in total.

For suspected immune deficient patients the best discrimination between visceral candidiasis and 8 colonisation was obtained by combining the results of haemagglutination inhibition and ara? binitol:creatinine ratio. For patients without signs of immune deficiency the best discriminatione between invasive candidiasis and colonisation was achieved with counterimmunoelectrophoresis." The results of the serological tests confirmed the classification on clinical grounds of those with and without immune deficiency.

Invasive, systemic, deep or disseminated candidiasis is a serious and often fatal complication that may occur in immune deficient patients. The development of systemic candidiasis may also be provoked by intravascular lines that are used for a long period, indwelling catheters, or after major surgery and antibacterial treatment. ${ }^{1-4}$

It is difficult to diagnose systemic candidiasis because there is no typical clinical picture. ${ }^{2}$ The infection can be confirmed only by organ biopsy, puncture of a normally sterile body fluid, or at necropsy; it is not demonstrable by positive cultures of blood ${ }^{5}$ and urine. Blood cultures are positive in no more than $40 \%$ of the cases of invasive candidiasis and can equally well point to a line infection. ${ }^{6}$ Recently it has been found that the serum concentration of D-arabinitol, a Candida specific metabolite, may help to diagnose invasive candidiasis. ${ }^{7-10}$

Accepted for publication 5 May 1987
It is important to diagnose tissue invasion at an early stage, as it can be successfully treated with amphotericin B. Each of the serological methods currently used for detecting antibodies and, to a lesser extent, circulating antigens has too low a sensitivity and specificity to distinguish sufficiently between invasive candidiasis and colonisation ${ }^{2411} 12$ and we thought that the sensitivity and specificity could be increased if the results of different methods were combined.

To distinguish invasive candidiasis from colonisation, the titres of three different antibodies and two different antigens were determined in the sera of patients with and without signs of immune deficiency. In addition, the quantity of circulating $D$-arabinitol was also measured in these patients. The purpose of the study was to investigate which reactions or combinations of reactions contributed most to the differentiation between invasive candidiasis and colonisation. 


\section{Material and methods}

From October 1982 to November 1985 sera were collected, where possible every week, from patients considered to be at risk and cultures made for the isolation of Candida sp from the throat, sputum, urine, faeces and vagina. Sera on which reaction tests were not carried out immediately were stored at $-70^{\circ} \mathrm{C}$. Blood samples for culture were taken regularly in cases of fever. When necropsy was performed specimens were taken from cauterised parenchymatous organs and from the gastrointestinal tract.

The case history notes of the patients were examined for diagnosis, course of disease, culture results, kidney function, leucopenia and treatment. On the basis of these data the patients were divided into two groups:

Group I consisted of 23 patients with confirmed invasive candidiasis. The diagnosis was based on culture specimens obtained by tissue biopsy, puncture of normally sterile body cavities, or necropsy specimens that were positive for Candida sp. One or more positive blood cultures were not considered sufficient evidence to classify a patient as having invasive candidiasis.

Group II consisted of 83 colonised patients without visible lesions. Colonisation was established by several positive open cultures of Candida species.

Each group was subdivided into patients with and without signs of immune deficiency. The criteria for immune deficiency were: histologically confirmed neoplasms, kidney function disorders requiring dialysis or treatment with corticosteroids, total body radiation, the use of immunosuppressive or cytotoxic drugs. As occult invasive candidiasis might have been present in the group of colonised patients, these patients were excluded from this group if fever of unknown origin did not react to antibiotics within three days; or if antifungal agents were being given. The administration of antifungal agents indicated that invasive candidiasis was thought to be the most likely diagnosis. The original number of colonised patients was therefore reduced from 83 to 33 . On the basis of these criteria, group I was divided into 13 patients with signs of immune deficiency (IA) and 10 patients without signs of immune deficiency (IB); the 33 colonised patients were divided into those with signs of immune deficiency (IIA) $(\mathrm{n}=26)$ and seven without signs of immune deficiency (IIB).

\section{ANTIBODY DETERMINATIONS}

The titres of agglutinating and haemagglutinating antibodies were determined by whole cell agglutination (WCA) and haemagglutination (HA). ${ }^{1314}$ Precipitating antibody titres were determined by counterimmunoelectrophoresis
(CIE). ${ }^{1516}$ In each case antigen was prepared from strain $C$ albicans, type A, No 5982. Whole cells killed by heat were used for WCA, and for HAI, a cytoplasmic antigen was prepared by yeast cell degradation using natamycin. ${ }^{17}$ For CIE, a cytoplasmic antigen was prepared with a Braun homogeniser.

\section{ANTIGEN DETERMINATIONS}

Titres of two different circulating antigens were determined by haemagglutination inhibition (HAI) and latex agglutination (LA). ${ }^{14-20}$ The latex test is commercially available as a kit (Ramco Laboratories Inc, Houston, Texas, USA). The same antigen was used for both HAI and HA. Rabbit immunoglobulins against $C$ albicans (Dako-immunoglobulins a/s, Copenhagen, Denmark) were used as antibodies. Rabbit Candida antibodies were used in the latex test.

\section{DETER MINATION OF D-ARABINITOL}

The serum concentrations of $\mathrm{D}$-arabinitol were determined by gas-liquid chromatography. The carbohydrates in serum were converted into trimethyl-silylether derivatives after removal of the proteins by acetone precipitation. The quantity of serum D-arabinitol was determined in relation to methylmannopyranoside, added as an internal standard $^{21}$ using a Packard series 428 gaschromatograph with a glass column (dimensions: $6 \times$ $1 / 4 \times 6 \mathrm{~mm}$; packing: $3 \%$ sillicone SE-30 on $80-100$ mesh. Gaschrom Q, Chrompack, Middelburg, The Netherlands). Nitrogen, the carrier gas, had a flow velocity of $40 \mathrm{ml} /$ minute, and a temperature gradient of $4^{\circ} \mathrm{C}$ /minute from $140^{\circ} \mathrm{C}$ to $220^{\circ} \mathrm{C}$ was set.

As the renal clearance of D-arabinitol is the same as that of creatinine the kidney function was corrected for by dividing the arabinitol concentration by the creatinine concentration. ${ }^{8}$ The figure thus obtained is known as the arabinitol:creatinine ratio (A:C).

The multiple logistic regression model was used in a discriminant analysis, ${ }^{22}$ which enables the (linear) combination of reactions which gives the best dicrimination between patients with and without invasive Candida infections to be found. In this statistical analysis one sided $p$ values were used, as the probabilities of invasive candidiasis will be more significant if higher reaction results are obtained. The serological reactions in the statistical analysis were compared by expressing the dilution steps in code (table 1).

\section{Results}

Tables 2 and 3 give the results obtained for 23 patients with confirmed invasive Candida infections. 
1164

Table 1 Coding of titres for statistical analysis

\begin{tabular}{lcclcl}
\hline Code & WCA & HA & CIE & HAI & Latex \\
\hline 0 & $<1: 20$ & $<1: 2$ & Negative & $<1: 2$ & Negative \\
1 & $1: 20$ & $1: 2$ & $1: 1$ & $1: 2$ & $1: 1$ \\
2 & $1: 40$ & $1: 4$ & $1: 2$ & $1: 4$ & $1: 2$ \\
3 & $1: 80$ & $1: 8$ & $1: 4$ & $1: 8$ & $1: 4$ \\
4 & $1: 160$ & $1: 16$ & $1: 8$ & $1: 16$ & $1: 8$ \\
5 & $1: 320$ & $1: 32$ & $1: 16$ & $1: 32$ & $1: 16$ \\
etc. & & & & & \\
\hline
\end{tabular}

The data for 13 patients with signs of immune deficiency are presented in table 2 , those for the 10 patients without signs of immune deficiency in table 3. The two tables show the highest titres for the available sera for each patient in the six tests. The highest titres of the six serological tests were not necessarily from the same serum.

Table 4 shows the data for the 26 colonised patients and table 5 those for the seven colonised patients. Table 6 gives the percentage of patients with a positive result in each of the tests. Not only can the tests differ widely from one another with regard to the results they yield, but the results yielded by a given test can vary widely between the different groups of pa-
Platenkamp, Duin, Porsius, Schouten, Zondervan, Michel tients. It could, none the less, be concluded that in the case of the 13 infected patients with signs of immune deficiency the tests for antigen and metabolite detection were more often positive than those for the detection of antibodies (table 6). The reverse seems to be true of the 10 infected patients without signs of immune deficiency. The data in table 6 formed the basis for the following evaluation of the different detection methods. The data for patients with and without signs of immune deficiency were analysed separately. This gave substantially better results than analysing the group as a whole. In the logistic model it was assumed that a positive test correlated with the diagnosis of visceral candidiasis.

PATIENTS WITH SIGNS OF IMMUNE DEFICIENCY Of the individual reactions, HAI was found to discriminate best between infected and colonised patients $(\mathrm{p}<0.05)$. Table 6 shows that the sensitivity of this reaction was $54 \%$ and the specificity $88 \%$. The predictive value of a positive result was $70 \%$.

Of the possible combinations of two reactions, HAI and A:C discriminated best (both $\mathrm{p}<0.05$ ). Table 7 lists the contributions of the results of the two

Table 2 Highest titres in 13 patients with signs of immune deficiency and a confirmed invasive candidiasis (class IA)

\begin{tabular}{|c|c|c|c|c|c|c|c|}
\hline Titre & $\begin{array}{l}* 1 / 160 \\
W C A\end{array}$ & $\begin{array}{l}1 / 64 \\
H A\end{array}$ & $\begin{array}{l}I / 2 \\
C I E\end{array}$ & $\begin{array}{l}I / 2 \\
H A I\end{array}$ & $\begin{array}{l}1 / 2 \\
\text { Latex }\end{array}$ & $\begin{array}{l}1 \cdot 50 \\
A: C\end{array}$ & Total \\
\hline Positive & $\begin{aligned} &< \frac{1 / 160}{1 / 20} \\
& 1 / 20 \\
&<1 / 20 \\
& 1 / 20 \\
& 1 / 40 \\
&<1 / 20 \\
& 1 / 80 \\
& 1 / 20 \\
&<1 / 20 \\
&<1 / 20 \\
&<1 / 20 \\
& \frac{1 / 320}{2 / 13}\end{aligned}$ & $\begin{aligned}< & 1 / 2 \\
< & 1 / 2 \\
& 1 / 4 \\
< & 1 / 2 \\
< & 1 / 2 \\
< & 1 / 2 \\
< & 1 / 2 \\
< & \frac{1 / 1024}{1 / 2} \\
& 1 / 8 \\
< & \frac{1 / 128}{1 / 2} \\
& \frac{1 / 2048}{3 / 13}\end{aligned}$ & $\begin{array}{l}\frac{1 / 2}{1 / 1} \\
\text { Negative } \\
1 / 1 \\
1 / 1 \\
\text { Negative } \\
1 / 1 \\
1 / 1 \\
1 / 1 \\
\text { Negative } \\
\text { Negative } \\
1 / 1 \\
\frac{1 / 4}{2 / 13}\end{array}$ & $\begin{aligned} & \frac{1 / 16}{1 / 160} \\
< & \frac{1 / 2}{1 / 8} \\
& \frac{1 / 4}{1 / 3} \\
< & \frac{1 / 2}{1 / 2} \\
< & 1 / 2 \\
< & \frac{1 / 16}{1 / 2} \\
< & 1 / 2 \\
< & \frac{1 / 2}{1 / 2} \\
& 7 / 13\end{aligned}$ & $\begin{array}{l}\frac{1 / 4}{\frac{1 / 4}{1 / 4}} \\
\frac{1 / 4}{N e g a t i v e ~} \\
\frac{1 / 1}{1 / 2} \\
\frac{1}{\text { Negative }} \\
\frac{1 / 4}{1 / 1} \\
\frac{1 / 8}{\text { Negative }} \\
\text { Negative } \\
\frac{1 / 2}{7 / 13}\end{array}$ & $\begin{array}{c}1.36 \\
\frac{1.97}{7.71} \\
0.86 \\
0.01 \\
0.82 \\
<\frac{22.4}{0.01} \\
\frac{4.8}{0.71} \\
1.16 \\
\frac{14.1}{0.72} \\
5 / 13\end{array}$ & $\begin{array}{l}+ \\
+ \\
+ \\
+ \\
+ \\
+ \\
+ \\
+ \\
+ \\
+ \\
+ \\
+ \\
+ \\
13 / 13\end{array}$ \\
\hline
\end{tabular}

*Limit values for positive titres. The positive outcomes are underlined.

Table 3 Highest titres in 10 patients without signs of immune deficiency with invasive candidiasis (class IB)

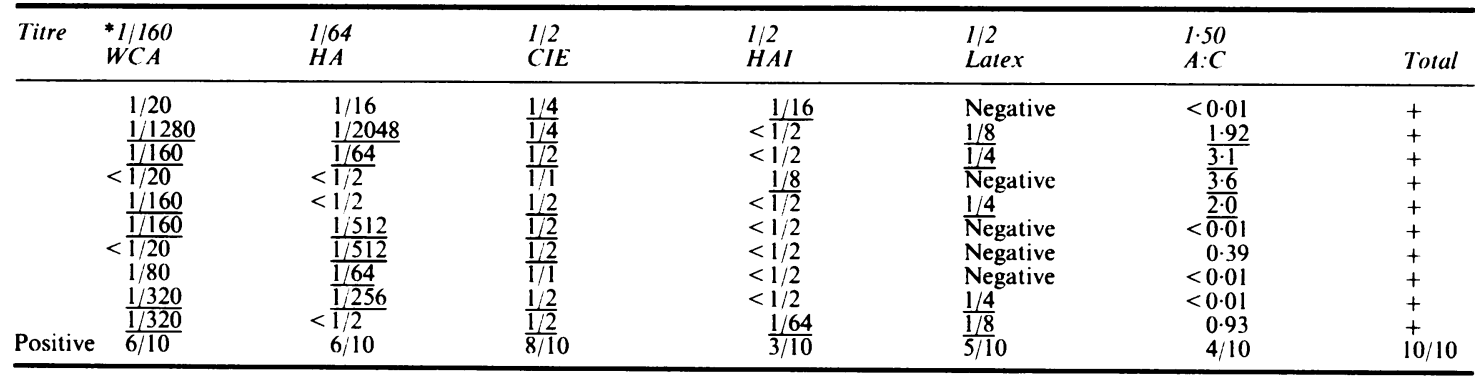

${ }^{*}$ Limit values for positive titres. The positive outcomes are underlined. 
Table 4 Highest titres in 26 patients with signs of immune deficiency and colonisation (class IIA) $\dagger$

\begin{tabular}{|c|c|c|c|c|c|c|c|}
\hline Titre & $\begin{array}{l}* 1 / 160 \\
W C A\end{array}$ & $\begin{array}{l}I / 64 \\
H A\end{array}$ & $\begin{array}{l}1 / 2 \\
C I E\end{array}$ & $\begin{array}{l}1 / 2 \\
H A I\end{array}$ & $\begin{array}{l}1 / 2 \\
\text { Latex }\end{array}$ & $\begin{array}{l}1 \cdot 50 \\
A: C\end{array}$ & Total \\
\hline Positive & $\begin{array}{rl} & \frac{1 / 160}{1 / 40} \\
< & 1 / 20 \\
& \frac{1 / 160}{1 / 40} \\
< & 1 / 20 \\
< & 1 / 20 \\
< & 1 / 20 \\
1 / 80 & <1 / 20 \\
< & 1 / 80 \\
< & 1 / 20 \\
< & 1 / 20 \\
< & 1 / 20 \\
& \frac{1 / 160}{1 / 320} \\
< & \frac{1 / 20}{1 / 20} \\
& 1 / 20 \\
1 / 160 & \frac{1}{1 / 20} \\
& 1 / 40 \\
& 1 / 40 \\
1 / 80 & 1 / 40 \\
< & 1 / 20 \\
1 / 80 & <1 / 20 \\
< & 5 / 26\end{array}$ & $\begin{array}{c}1 / 32 \\
1 / 4 \\
1 / 2 \\
<1 / 2 \\
<1 / 2 \\
<1 / 2 \\
<1 / 2 \\
<1 / 2 \\
1 / 32 \\
1 / 16 \\
1 / 16 \\
1 / 16 \\
<1 / 2 \\
1 / 4 \\
\frac{1 / 64}{1 / 2} \\
<1 / 2 \\
<1 / 2 \\
<\frac{1 / 256}{1 / 2} \\
1 / 16 \\
<1 / 2 \\
\frac{1 / 128}{1 / 8} \\
1 / 32 \\
<1 / 2 \\
3 / 26\end{array}$ & $\begin{array}{l}\frac{1 / 2}{\text { Negative }} \\
1 / 1 \\
1 / 1 \\
1 / 1 \\
1 / 1 \\
1 / 1 \\
1 / 1 \\
1 / 1 \\
1 / 1 \\
\frac{1 / 2}{1 / 1} \\
1 / 1 \\
\text { Negative } \\
\frac{1 / 2}{1 / 2} \\
\frac{\text { Negative }}{\text { Negative }} \\
\frac{1 / 2}{\text { Negative }} \\
\text { Negative } \\
\text { Negative } \\
1 / 1 \\
\text { Negative } \\
\frac{1 / 2}{\text { Negative }} 6 / 26 \\
6 / 26\end{array}$ & $\begin{array}{rl}<1 / 2 & 1 / 8 \\
& \frac{1}{1 / 4} \\
< & 1 / 2 \\
<1 / 2 & <1 / 2 \\
<1 / 2 \\
<1 / 2 \\
<1 / 2 \\
<1 / 2 \\
<1 / 2 \\
<1 / 2 \\
<1 / 2 \\
<1 / 2 \\
<1 / 2 \\
<1 / 2 \\
<1 / 2 \\
<1 / 2 \\
<1 / 4 \\
<1 / 2 \\
<1 / 2 \\
<1 / 2 \\
<1 / 2 \\
<1 / 2 \\
<1 / 2 \\
<1 / 2 \\
<1 / 2 \\
<1 / 2 \\
<1 / 2 \\
<1 / 2 \\
3 & 3 / 26\end{array}$ & $\begin{array}{l}\text { Negative } \\
\frac{1 / 2}{\text { Negative }} \\
\frac{1 / 8}{\text { Negative }} \\
\frac{1 / 8}{\text { Negative }} \\
\text { Negative } \\
\text { Negative } \\
\text { Negative } \\
\frac{1 / 4}{\text { Negative }} \\
\text { Negative } \\
\text { Negative } \\
\frac{1 / 8}{1 / 4} \\
\frac{\text { Negative }}{1 / 2} \\
\frac{\text { Negative }}{\text { Negative }} \\
\text { Negative } \\
1 / 1 \\
\text { Negative } \\
\text { Negative } \\
\text { Negative } \\
\text { Negative } \\
7 / 26\end{array}$ & $\begin{array}{r}<0.01 \\
<0.01 \\
<0.01 \\
<0.01 \\
0.80 \\
0.40 \\
<0.01 \\
<0.01 \\
<0.01 \\
<0.01 \\
0.79 \\
1.86 \\
<0.01 \\
<0.01 \\
<0.01 \\
0.62 \\
0.44 \\
<0.01 \\
4.27 \\
<\overline{4} 0.01 \\
<0.01 \\
1.89 \\
<0.01 \\
33.76 \\
<0.01 \\
<0.01 \\
4 / 26\end{array}$ & $\begin{array}{l}+ \\
+ \\
+ \\
+ \\
\text { Negative } \\
+ \\
\text { Negative } \\
\text { Negative } \\
\text { Negative } \\
\text { Negative } \\
+ \\
+ \\
\text { Negative } \\
\text { Negative } \\
+ \\
+ \\
+ \\
+ \\
+ \\
\text { Negative } \\
\text { Negative } \\
+ \\
+ \\
+ \\
+ \\
\text { Negative } \\
16 / 26\end{array}$ \\
\hline
\end{tabular}

* Limit values for positive titres. + Excluding patients with clinical indications of, or suspected visceral candidiasis.

tests. Eight of the 13 patients (IA) with invasive candidiasis are below and to the right of the stepped dividing line indicating that the sensitivity was increased to $62 \%$ for the combination of HAI and A:C ratio. All 26 colonised patients (IIA) were correctly determined, indicating a specificity of $100 \%$ and a predictive value of a positive result for the combination of $\mathrm{HAI}$ and $\mathrm{A}: \mathrm{C}$ ratio also of $100 \%$.

Of the combinations of three reactions, HAI, A:C ratio and HA discriminated best $(p<0.05)$. Two patients had high HA titres of $1 / 1024$ and 1/2048 (table 2). Thanks to those high titres these patients were diagnosed as having invasive candidiasis. The results of $\mathrm{HAI}$ and A:C ratio alone would have classified these patients as colonised. The combination of HAI, A:C ratio, and HA raised the sensitivity from $62 \%$ for the combination of $\mathrm{HAI}$ and $\mathrm{A}: \mathrm{C}$ ratio to $77 \%$. The specificity and the predictive value of a positive result remained at $100 \%$.

A diagnosis of visceral candidiasis can be ruled out by using a combination of two reactions. This can be done by putting the $\mathrm{A}: \mathrm{C}$ ratio at $<0.01$ and $\mathrm{HAI}$ at $<1: 2$. The sensitivity is thereby raised to $92 \%$; only one patient (IA) had a negative result. The specificity, however, was only $58 \% ; 15$ of the 26 colonised patients had negative results. The predictive value of a negative result was therefore $94 \%$.

\section{PATIENTS WITHOUT SIGNS OF IMMUNE DEFICIENCY}

A significant correlation was obtained only between a positive CIE result and deep candidiasis $(\mathrm{p}<0.05)$. Taking a positive cut off value of $1 / 2$, the sensitivity of CIE was $80 \%(n=10)$. The specificity of this reac-

Table 5 Highest titres in seven colonised patients without signs of immune deficiency (class IIB)

\begin{tabular}{|c|c|c|c|c|c|c|c|}
\hline Titre & $\begin{array}{l}* 1 / I 60 \\
W C A\end{array}$ & $\begin{array}{l}I / 64 \\
H A\end{array}$ & $\begin{array}{l}l / 2 \\
C I E\end{array}$ & $\begin{array}{l}I / 2 \\
H A I\end{array}$ & $\begin{array}{l}1 / 2 \\
\text { I.atex }\end{array}$ & $\begin{array}{l}1 \cdot 50 \\
A: C\end{array}$ & Total \\
\hline 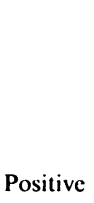 & $\begin{array}{r}1 / 20 \\
1 / 80 \\
1 / 80 \\
<1 / 20 \\
<1 / 20 \\
1 / 20 \\
1 / 40 \\
0 / 7\end{array}$ & $\begin{aligned} & 1 / 8 \\
< & \frac{1 / 64}{1 / 2} \\
< & 1 / 2 \\
& 1 / 8 \\
& \frac{1 / 256}{1 / 64} \\
& \frac{1 / 7}{3 / 7}\end{aligned}$ & $\begin{array}{l}1 / 1 \\
1 / 2 \\
1 / 1 \\
1 / 1 \\
\text { Negative } \\
\text { Negative } \\
\text { Negative } \\
1 / 7\end{array}$ & $\begin{aligned} & \frac{1 / 128}{<} \\
< & 1 / 2 \\
< & 1 / 2 \\
< & 1 / 2 \\
< & 1 / 2 \\
< & 1 / 2 \\
& 1 / 2 \\
& 1 / 7\end{aligned}$ & 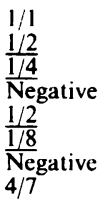 & $\begin{array}{r}1.42 \\
<0.01 \\
<0.01 \\
<0.01 \\
<0.01 \\
<0.01 \\
0.77 \\
0 / 7\end{array}$ & $\begin{array}{l}+ \\
+ \\
+ \\
\text { Negative } \\
+ \\
+ \\
+ \\
6 / 7\end{array}$ \\
\hline
\end{tabular}

* Limit values for positive titres. The positive outcomes are underlined. 
Table 6 Percentage of patients with positive results*

\begin{tabular}{|c|c|c|c|c|c|c|c|}
\hline \multirow[b]{2}{*}{ Category } & \multirow{2}{*}{$\begin{array}{l}\text { No of } \\
\text { patients }\end{array}$} & \multicolumn{6}{|c|}{ Percentage } \\
\hline & & $W C A$ & $H A$ & CIE & $H A I$ & $L A$ & $A: C$ \\
\hline $\begin{array}{r}\text { IA } \\
\text { IIA } \\
\text { IB } \\
\text { IIB }\end{array}$ & $\begin{array}{r}13 \\
26 \\
10 \\
7\end{array}$ & $\begin{array}{r}15 \\
19 \\
60 \\
0\end{array}$ & $\begin{array}{l}23 \\
12 \\
60 \\
43\end{array}$ & $\begin{array}{l}15 \\
23 \\
80 \\
14\end{array}$ & $\begin{array}{l}54 \\
12 \\
30 \\
14\end{array}$ & $\begin{array}{l}54 \\
27 \\
50 \\
57\end{array}$ & $\begin{array}{r}38 \\
15 \\
40 \\
0\end{array}$ \\
\hline
\end{tabular}

*Value equal to or greater than the limit value.

tion was $86 \%(n=7)$ and the predictive value of a positive result $89 \%$. The number of patients, however, was small.

\section{Discussion}

Serological detection of antibodies can fail because the patient can not produce an adequate immune response or because the first serum sample is taken before antibodies have been formed. Moreover, high titres can be the result of colonisation of Candida sp. Antigen detection methods in serum are also insufficiently sensitive and specific to distinguish between a systemic infection and colonisation. Determination of the concentration of the Candida specific metabolite D-arabinitol in serum now seems to represent an important advance in the detection of deep candidiasis.

For those patients with signs of immune deficiency reported in this study, HAI and LA were the most sensitive discriminators between invasive candidiasis and colonisation, but HAI had a greater specificity than LA. Although a cut off point of $1 / 4$ has been advocated for LA, ${ }^{18}$ in the present study logistic regression analysis pointed to a positive borderline value for this reaction of $1 / 2$. Using latex particles coated with rabbit antibody to a partially heat labile candidal antigen, the most efficient titres for diagno- sing leukaemia or lymphoma amounted to $1 / 8$, for medical or surgical patients to $1 / 10 .^{23}$ An immune response was much more likely to occur in the early stages of the disease in both categories of patients, which agrees with the findings of Kahn and Jones. ${ }^{24}$ Theoretically, antigen detection should be more sensitive in the group with signs of immune deficiency because there are fewer antibodies to bind to the antigens, but this varies from person to person as antigenaemia seems to be a transient phenomenon during the infection. ${ }^{24} 25$

In the patients without signs of immune deficiency, CIE discriminated best between systemic infection and colonisation. For those with signs of immune deficiency, combining the results of $\mathrm{HAI}$ and $\mathrm{A}: \mathrm{C}$ ratio increased sensitivity to $62 \%$, compared with $54 \%$ for HAI alone. The predictive value of the combination was $100 \%$. Though the addition of $\mathrm{HA}$ to the HAI-A:C combination raised the sensitivity to $77 \%$, this was due to only two patients. A sensitivity of $77 \%$ is not optimal for the serological diagnosis of infections. Therefore, a negative serological result obtained with $\mathrm{HAI}<1 / 2$ and $\mathrm{A}: \mathrm{C}<0.01$ rules out the diagnosis of visceral candidiasis in $92 \%$ of the infected patients. In the case of the patients without signs of immune deficiency no combination of reactions gave significantly better discrimination than CIE. The logistic model, however, provided some indication

Table 7 No of patients with signs of immune deficiency with (class IA) and without (class IIa: colonisation of patients) invasive candidiasis related to $A: C$ ratio and $H A I$

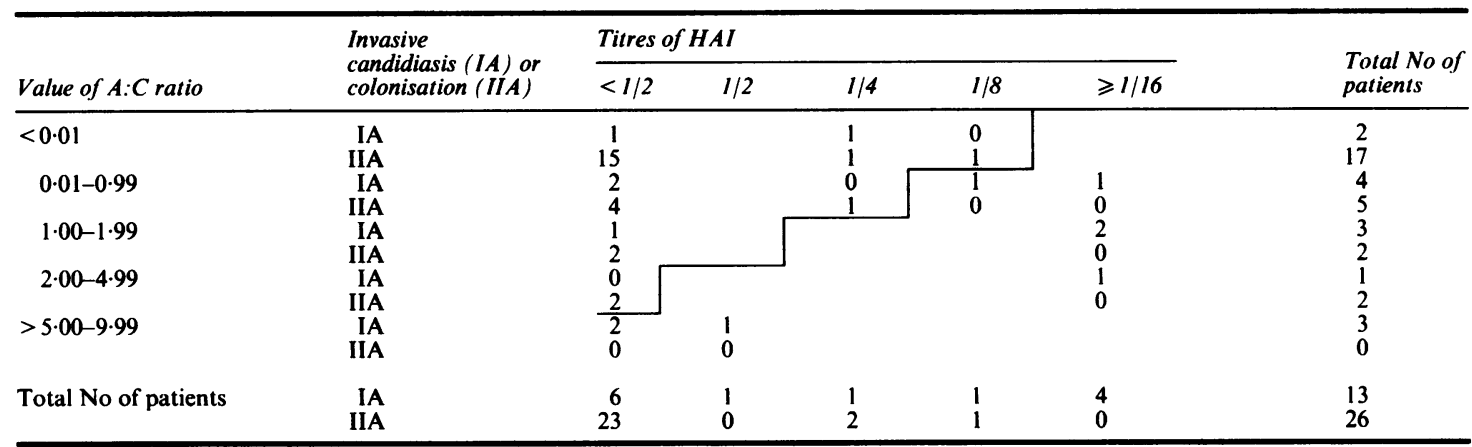

The stepped line distinguishes between patients with deep candidiasis (below right) and colonised patients (above left). HAI dilution steps are shown horizontally; the A:C ratios are shown vertically. 
that the combination of $\mathrm{CIE}$ and $\mathrm{A}: \mathrm{C}$ ratio might give better discrimination with a larger number of patients. Gold et $a l^{9}$ obtained encouraging results with the measurement of the $\mathrm{A}: \mathrm{C}$ ratio in cancer patients with invasive candidiasis. It should be mentioned, however, that they did not evaluate the A:C ratio in patients who were merely colonised. In a nonprospective study Holak et $\mathrm{al}^{\mathbf{2 6}}$ were unable to distinguish invasive from superficial candidiasis by $\mathrm{A}: \mathrm{C}$ ratio alone. According to the results in our study $\mathrm{A}: \mathrm{C}$ ratio could become an important diagnostic factor for both patients with and without signs of immune deficiency. The method, however, is cumbersome for use in the routine of a bacteriological laboratory, a problem that could perhaps be circumvented by using a spectrophotometric detection method of Darabinitol, as described by Soyama and Ono. ${ }^{27} \mathrm{As}$ in this study, Fisher et $a^{25}$ also used a combination of detection methods of antibodies and antigens to differentiate patients with confirmed disseminated candidal infection. Although they obtained good results, these cannot easily be compared with ours because different techniques were used, different patient categories were compared, and no distinction was made between the presence or absence of signs of immune deficiency.

In future, other approaches may also contribute to discrimination between invasive candidiasis and colonisation. Using immunoblot analysis, Matthews et $a l^{28}$ found several patterns of antibody response in systemic candidiasis. On the other hand, ManningZweerink $e{ }^{a l^{29}}$ observed a great variability in $\mathrm{Calbi}$ cans specific antibodies in patients with confirmed or suspected candidiasis. De Repetigny and Reiss ${ }^{30}$ pointed to the possible use of monoclonal antibodies to characterise circulating Candida antigens.

We thank Mrs AL Beukelman for typing the manuscript.

\section{References}

I Edwards JE, Lehrer RI, Fieher TJ, Young LS. Severe Candidal infections: clinical perspective, immune defense mechanisms, and current concepts of therapy. Ann Intern Med 1978;89:91-106.

2 Odds FC. Candida and candidosis. Baltimore: University Park Press, 1979:76, 132-4, 218-25.

3 Meunier-Carpentier F, Kiehn TE, Armstrong D. Fungemia in the immunocompromised host. Am J Med 1981;71:363-70.

4 Bodey GP, Fainstein V. Candidiasis. New York: Raven Press, 1985:53-4, 99-104.

5 Young RC, Bennet JE, Geelhoed GW, Levine AS. Fungemia with compromised host resistance. Ann Intern Med 1974;80:605-12.

6 Bodey GP. Candidiasis in cancer patients. Am J Med 1974;77(suppl 4D): 13-9.

7 Wong B, Bernard EM, Gold JWM, Fong D, Silber A, Armstrong D. Increased arabinitol levels in experimental candidiasis in rats: arabinitol appearance rates, arabinitol/creatinine ratios, and severity of infection. J Infect Dis 1982a;146:346-52.

8 Wong B, Bernard EM, Gold JWM, Fong D, Armstrong D. The arabinitol appearance rate in laboratory animals and humans: estimation from the arabinitol/creatinine ratio and relevance to the diagnosis of candidiasis. J Infect Dis 1982b;146:353-9.

9 Gold JWM, Wong B, Bernard EM, Kiehn FE, Armstrong D. Serum arabinitol concentrations and arabinitol:creatinine ratios in invasive candidiasis. $J$ Infect $D i s$ 1983;147:504-13.

10 Wells CL, Sirany MS, Blazevic DJ. Evaluation of serum arabinitol as a diagnostic test for candidiasis. J Clin Microbiol 1983;18:353-7.

11 Weiner MH, Yount WJ. Mannan antigenemia in the diagnosis of invasive Candida infections. J Clin Invest 1976;58:1045-53.

12 Araj GF, Hopfer RH, Chesnut S, Fainstein V, Bodey GP. Diagnostic value of the enzyme-linked immunosorbent assay for detection of Candida albicans cytoplasmic antigen in sera of cancer patients. J Clin Microbiol 1982;16:46-52.

13 Harding SA, Sandford GR, Merz WG. Three serologic tests for candidiasis. Am J Clin Pathol 1976;65:1001-9.

14 Meunier-Carpentier F, Armstrong D. Candida antigenemia, as detected by passive hemagglutination, in patients with disseminated candidiasis of Candida colonization. J Clin Microbiol 1981;13:10-4.

15 Marier R, Andriole VT. Comparison of continuous and discontinuous counterimmunoelectrophoresis with immunodiffusion in identification of Candida antibody using HS antigen. J Clin Microbiol 1978a;8:12-4.

16 Marier R, Andriole VT. Usefulness of serial antibody determinations in diagnosis of candidiasis as measured by discontinuous counterimmunoelectrophoresis using HS antigen. J Clin Microbiol 1978b;8:15-22.

17 Holliday M. A modified cytoplasmic antigen of Candida albicans for serodiagnosis of systemic candidiasis. J Immunol Methods 1979;31:71-81.

18 Gentry LO, Wilkinson ID, Lea AS, Price MF. Latex agglutination test for detection of Candida antigen in patients with disseminated disease. Eur J Clin Microbiol 1983;2:122-8.

19 Bailey JW, Sada E, Brass E, Bennett JE. Diagnosis of systemic candidiasis by latex agglutination for serum antigen. $J$ Clin Microbiol 1985;21:749-52.

20 Burnie JP, Williams JD. Evaluation of the Ramco latex agglutination test in the early diagnosis of systemic candidiasis. Eur $J$ Clin Microbiol 1985;4:98-101.

21 Kiehn TE, Bernard EM, Gold JWM, Armstrong D. Candidiasis: detection by gas-liquid chromatography of D-arabinitol, a fungal metabolite, in human serum. Science 1979;206:577-80.

22 Polock SJ. Clinical trials. A practical approach. Chichester: John Wiley \& Sons, 1986.

23 Burnie J. A reverse passive latex agglutination test for the diagnosis of systemic candicosis. J Immunol Methods 1985;82:267-80.

$24 \mathrm{Kahn}$ FW, Jones JM. Latex agglutination tests for detection of Candida antigens in sera of patients with invasive candidiasis. $J$ Infect Dis 1986;153:579-85.

25 Fisher JF, Trincher RC, Agel JF, et al. Disseminated candidiasis: a comparison of two immunologic techniques in the diagnosis. Am J Med Sci 1985;290:135-42.

26 Holak EJ, Wu JW, Spruance SL. Value of serum arabinitol for the management of Candida infections in clinical practice. Mycopathologia 1986;93:99-104.

27 Soyama K, Ono E. Enzymatic fluorometric method for the determination of $D$-arabinitol in serum by initial rate analysis. Clin Chim Acta 1985;149:149-54.

28 Matthews RC, Burnie JP, Tabaqchali S. Immunoblot analysis of the serological response in systemic candidiasis. Lancet 1984;ii:1415-8.

29 Manning-Zweerink M, Malony CS, Mitchel TG, Weston H. Immunoblot analysis of Candida albicans associated antigens and antibodies in human sera. $J$ Clin Microbiol 1986;23:46-52.

30 Repetigny $L$ de, Reiss E. Current trends in immunodiagnosis of candidiasis and aspergillosis. Rev Infect Dis 1984;6:301-12.

Requests for reprints to: Dr GJ Platenkamp, Department of Clinical Microbiology, Erasmus University, Rotterdam. PO Box 1738, 3000 DR Rotterdam, The Netherlands. 